\title{
The Development of the Physical Fundamentals of Contact Soldering as a Factor for Reducing the Number of Defects in Electronic Devices
}

\author{
V. N. Shtennikov ${ }^{a}$ and B. T. Budai ${ }^{b}$ \\ ${ }^{a}$ El'tsin Ural Federal University, Yekaterinburg, Russia \\ ${ }^{b}$ Physico-Technical Institute, El'tsin Ural Federal University, Yekaterinburg, Russia \\ e-mail: Stennikov_vn@mail.ru,buda@olympus.ru \\ Received November 9, 2012
}

\begin{abstract}
Automated control systems employ electronic components that are connected with a printed circuit board (PCB) by soldered joints. At elevated temperatures and with high vibration levels, soldering defects may occur that are characterized by the deterioration or complete loss of contact with the PCB, which can lead to the failure of the system. In this work, an approach is proposed to considerably improve the reliability of soldered joints.
\end{abstract}

Keywords: defect, quality, diagnostics, comparison, heat transfer, soldering

DOI: $10.1134 / \mathrm{S} 1061830913030078$

\section{INTRODUCTION}

Failures of automated systems are primarily due to defects of soldered joints. The development of the next automated system that incorporates new design and engineering solutions determines the use of soldered joints. On the other hand, an analysis of the technical literature and corresponding international standards that deal with the contact soldering of electronic devices shows that they contain only the most general information on the influence of the parameters of soldering tools on the contact soldering temperature.

As far as we are aware, the presence of a sole unique soldered joint in an electronic device implies the use of nonstandard soldering conditions or a nonstandard soldering tool, which is not applied in practice. As a result, complex electronic devices fail, in the best case, at the testing stage and in the worst case, during operation. The situation is complicated by the fact that the majority of organizations and enterprises no longer have soldering laboratories.

Thus, the development of physical fundamentals of up-to-date manufacturing processes and technical diagnostics is of crucial significance [1-3].

The importance of the use of automated systems for controlling the parameters of manufacturing processes is progressively increasing, especially under ever more complicated operating conditions, e.g., at elevated temperatures and high vibration levels. For example, during the quality control of parameters of flats, an automated control system operates at elevated temperatures and high vibration levels [4]. Therefore, the search for solutions that reduce the number of defects of soldered joints in electronic devices that operate at elevated temperatures and high levels of vibration is of a great significance.

Figures 1 and 2 show sections of joints that were produced at optimal and lower soldering temperatures, respectively.

Among other factors, such as the duration of soldering, the gap between the parts, the solderability of the surfaces, the flux used, etc., the soldering temperature is known to have a decisive effect on joint quality [5]. It should be noted that a decrease in the soldering temperature and in the duration of soldering can result in a poor wettability of the surfaces that are being soldered, while an increase in these parameters may lead to the formation of a fairly brittle $\mathrm{Cu}_{6} \mathrm{Sn}_{5}$ intermetallic layer that is more than $0.5 \mu \mathrm{m}$ thick, as well as to the overheating of the components $[5,6]$.

Therefore, when using POS61 solder, it is recommended that the temperature of the contact soldering of electronic devices be kept in the $230-270^{\circ} \mathrm{C}$ range. The application of lead-free solders is substantially narrower this range [6]. 


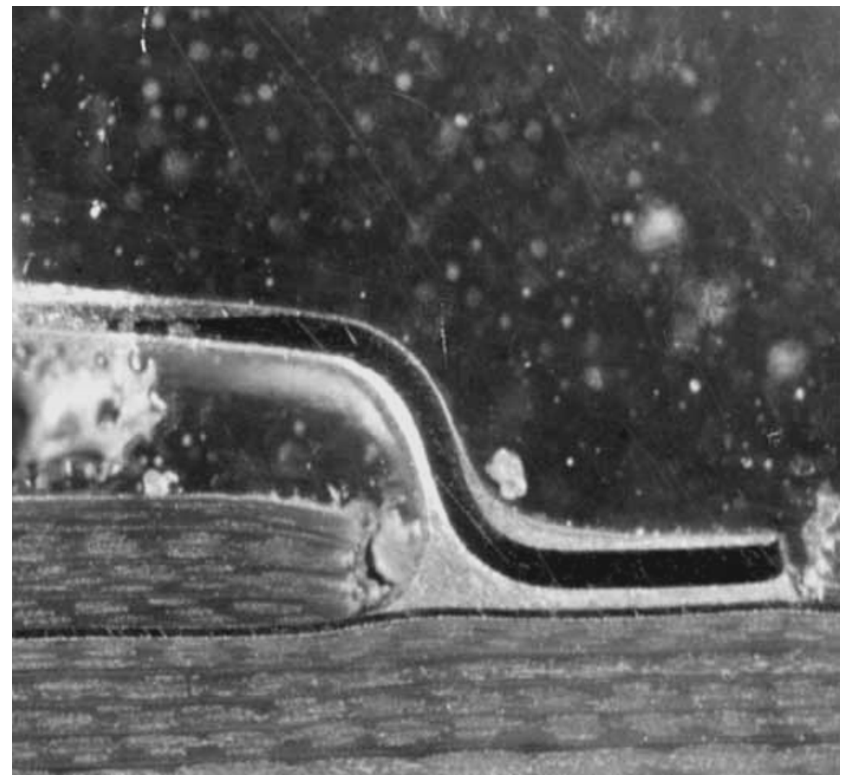

Fig. 1. A section of soldered joint between the chip lead and contact pad of a multilayered printed circuit board.

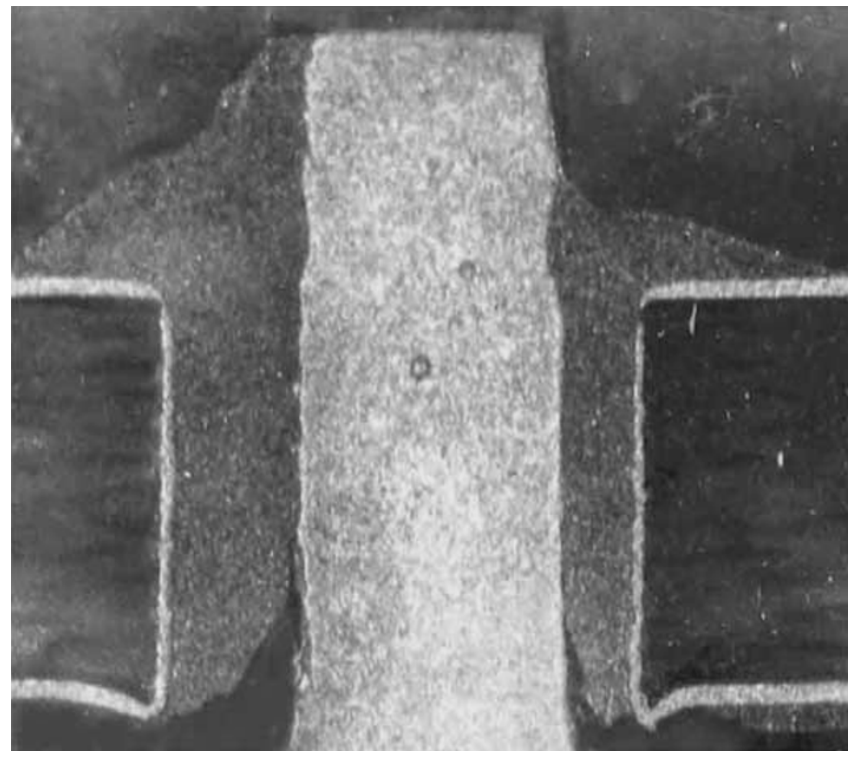

Fig. 2. A section of a soldered joint produced at a lower elevated temperature.

Despite the wide adoption of mechanized and automated soldering methods, hand soldering tools are indispensable during pilot production, as well as the repair, adjustment, and setting of electronic devices. Contact soldering by heated tools or equipment is indispensable when carrying out so-called point-topoint wiring or space-wired interconnections. Under these conditions, in order to provide the required temperature of the contact soldering of electronic and electrical devices, the temperature of a tool before the soldering process is controlled [6].

In order to compensate for heat removal to a soldered joint, the temperature of the rod of a soldering tool is usually increased by $20-40^{\circ} \mathrm{C}$ with regard to the required soldering temperature. This is sufficient for production of the majority of standard soldered joints. However, the heat absorption of nonstandard electrical joints can substantially differ from the average value, which makes it impossible to ensure highquality soldering. 


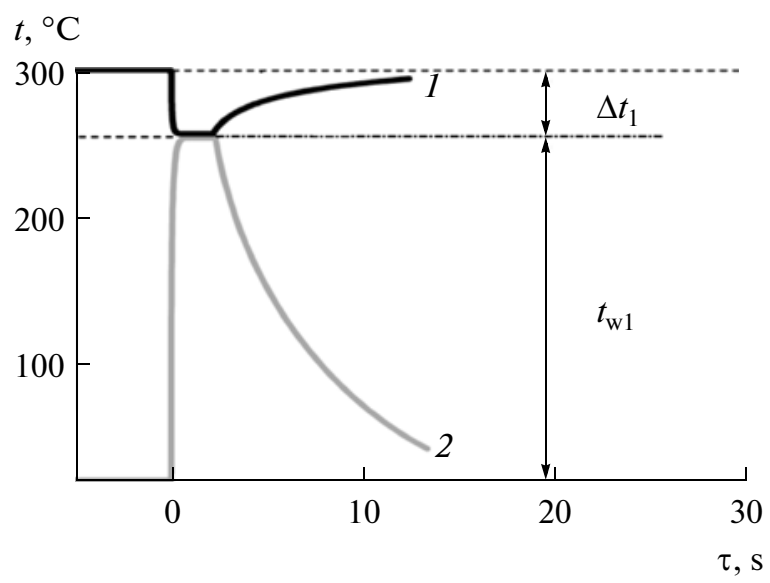

Fig. 3. Variations in the temperature of the working end of a soldering-tool rod and a soldered joint of two wires during and after a single soldering procedure.

The decrease in the temperature of the working end of a soldering station rod during its contact with a soldered joint can reach a few tens of degrees and therefore the soldering temperature is practically uncontrolled. Some researchers propose to solve the problem of keeping an optimal soldering temperature by selecting a soldering tool type or an optimal temperature before the soldering process, or a combination of both [7].

The methods that are proposed are, first, fairly labor-consuming and, second, insufficiently objective.

Thus, the urgency of the problem is due to the following factors:

- The profound effect of the quality of soldered joints on the reliability of an electronic device as a whole;

- The large number and a wide variety of designs of soldered joints in electronic devices, which leads to the use of original equipment and various soldering methods;

- The complex dependences of the parameters of the soldering process on the equipment parameters;

-Errors in the technical literature and regulations that are relevant to this issue, including the IPC and IEC international standards;

- The absence of scientifically substantiated recommendations for keeping and predicting optimal soldering conditions, as well as for solving problems of ensuring these conditions.

\section{THE COOLING OF A LONG ROD DURING SOLDERING}

On the basis of a comparison of the time constants of cooling for a soldering rod that contacts air and a soldered joint, it has been found that ignoring the heat transfer from the rod to the air leads to an error of less than $1 \%$ when describing variations in the temperature of the rod's working end, which contacts the joint; this is a few times less than the experimental error.

Figure 3 shows variations in the temperatures of the working end of the soldering tool rod (curve 1 ) and the soldered joint of two wires (curve 2) during and after single soldering.

During fairly long breaks between soldering procedures, we will suppose that the working end of a soldering rod with a constant cross-sectional area has a steady idle temperature $t_{1}$ and a wire that is being soldered or maintained has the temperature $t_{2}=0$. At the time $\tau=0$, thermal contact between the working end of the soldering rod with the wire end occurs. The rod is directed to one end of the axis $(x>0)$; the wire, to the other end $(x<0)$. Let us assume that the rod and wire are heat insulated and have infinite lengths, i.e.,

$$
\left(\frac{\partial t}{\partial x}\right)_{x=+\infty}=\left(\frac{\partial t}{\partial x}\right)_{x=-\infty}=0, \quad t_{x=+\infty}=t_{1}, \quad t_{x=-\infty}=t_{2} .
$$

On the assumption that no heat transfer from the soldering rod and soldered joint to air occurs and neglecting the temperature gradient in the cross sections of the rod and wire, the heat conduction equations can be written as follows: 


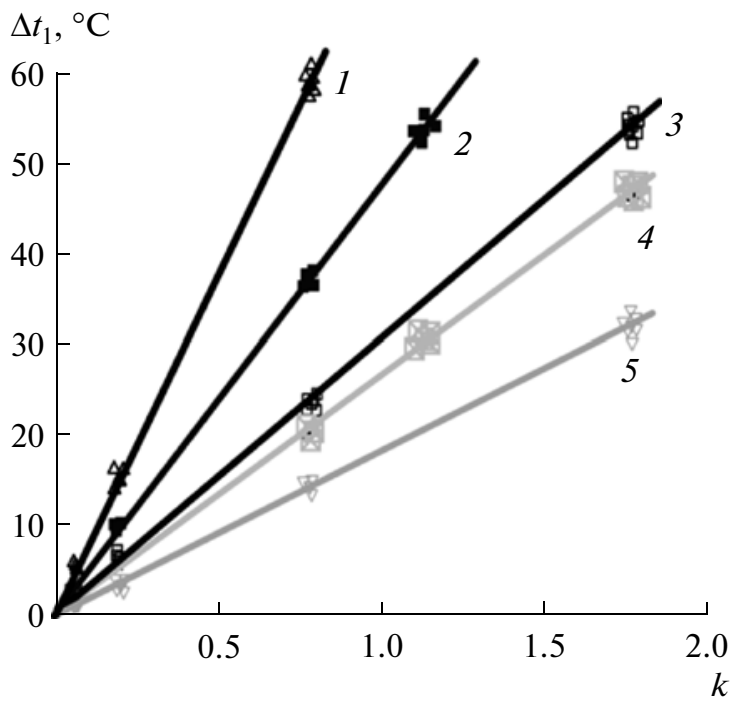

Fig. 4. The dependences of $\Delta t_{1}$ on $k=S_{2} \sqrt{(\lambda \rho c)}_{2} / \sqrt{(\lambda \rho c)_{1}}:(1,3,5)$ copper rod 2, 3, and 4 mm in diameter, respectively; (2) steel 15 rod $4 \mathrm{~mm}$ in diameter; (4) an aluminum AB97 rod $4 \mathrm{~mm}$ in diameter.

$$
\frac{d^{2} t_{1}}{d x^{2}}=\frac{1}{a_{1}} \frac{d t_{1}}{d \tau}, \quad \frac{d^{2} t_{2}}{d x^{2}}=\frac{1}{a_{2}} \frac{d t_{2}}{d \tau}
$$

The temperatures of the contact points of the soldering rod and the wire are equal and at the boundary of the contact the heat-balance equation is as follows:

$$
-\left.S_{1} \lambda_{1} \frac{d t_{1}}{d x}\right|_{x=+0}=-\left.S_{2} \lambda_{2} \frac{d t_{2}}{d x}\right|_{x=-0}
$$

Using data from [8], the solutions of heat-conduction equations with initial and boundary conditions that were presented can be written in the following form:

$$
\begin{gathered}
\Delta t_{1}=t_{\mathrm{w} 1} \frac{S_{2} \sqrt{\lambda_{2} \rho_{2} c_{2}}}{S_{1} \sqrt{\lambda_{1} \rho_{1} c_{1}}}, \\
\Delta t_{1(x, \tau)}=\Delta t_{1}\left\{1-\Phi\left(\frac{x}{2 \sqrt{a_{1} \tau}}\right)\right\},
\end{gathered}
$$

where $\tau$ is the time, $\mathrm{s} ; \Delta t_{1}=t_{x x}-t_{\mathrm{w} 1}$ is a decrease in the temperature of the working end of a long soldering $\operatorname{rod}\left(L \geq 1.6 \sqrt{a \tau_{\mathrm{w}}}\right)$ during a single soldering procedure, ${ }^{\circ} \mathrm{C} L$ is the soldering-rod length, $\mathrm{m} ; a$ is the thermal diffusivity, $\mathrm{m}^{2} \mathrm{~s}^{-1} ; t_{1}$ is the excess temperature of the rod's working end, ${ }^{\circ} \mathrm{C} ; t_{2}$ is the excess temperature of the soldered joint, ${ }^{\circ} \mathrm{C} ; t_{\mathrm{w} 1}$ is the excess temperature of the rod's working end during a single soldering procedure, ${ }^{\circ} \mathrm{C}$; $c$ is the specific heat, $\mathrm{J} \mathrm{kg}^{-1}{ }^{\circ} \mathrm{C}^{-1} ; d_{1}$ is the diameter of the soldering tool rod, $\mathrm{m} ; S_{1}$ is the cross-sectional area of the soldering tool, $\mathrm{m}^{2} ; S_{2}$ is the cross-sectional area of the soldered joint, $\mathrm{m}^{2} ; \rho$ is the density, $\mathrm{kg} \mathrm{m}^{-3} ; \lambda$ is the thermal conductivity, $\mathrm{W} \mathrm{m}^{-1}{ }^{\circ} \mathrm{C}^{-1}$; and $\Phi(u)=\frac{2}{\sqrt{\pi}} \int_{0}^{\mu} e^{-\xi^{2}} d \xi$ is the probability integral.

It follows from equation (1) that during contact with the soldered joint the decrease in the temperature of the working end of the soldering rod is proportional to the cross-sectional area of the wire that is being soldered and inversely proportional to the cross-sectional area of the soldering rod. 


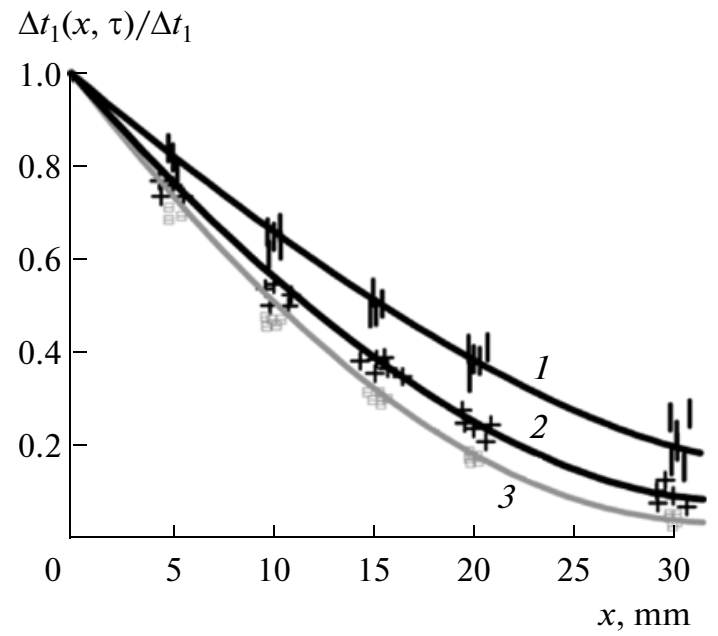

Fig. 5. The decrease in the temperature of a soldering rod with length $L \geq 1.6 \sqrt{a \tau_{\mathrm{w}}}$ and constant diameter with increasing distance from the working end at various durations of soldering: (1) 2.7 ; (2) 1.4 ; (3) $1.0 \mathrm{~s}$.

\section{MEASUREMENT METHODS}

To verify the correctness of expressions (1) and (2), we carried out experiments using soldering tools with powers of 6-1000 $\mathrm{W}$. These had soldering rods that were 50-100 $\mathrm{mm}$ long and 2-4 $\mathrm{mm}$ in diameter; the duration of the soldering was $0.3-5 \mathrm{~s}$.

Figure 4 and 5 illustrate the experimental results. In Figure 4, the solid lines show the curves calculated by formula (1) and the symbols show the experimental data.

The temperature was measured by a Chromel-Copel thermocouple with the wires $0.2 \mathrm{~mm}$ in diameter. The thermal e.m.f. was recorded by a KSP-4 potentiometer of the 0.25 accuracy class. The error of temperature measurement was $\pm 1^{\circ} \mathrm{C}$. The duration of soldering $(0.3-5.0 \mathrm{~s})$ was determined by an STTs 1 electronic stopwatch timer with an error of $\pm 0.02 \mathrm{~s}$. The agreement of the experimental data with the calculated values to within the experimental error (about 6\%) confirmed the adequacy of the model that was selected for the processes under study.

The quality of soldered joints that are produced with allowance for expressions (1) and (2) was evaluated using the following methods: by visual observation in a MBS-2 microscope with a magnification of $(25-50)^{X}$; by examining the shapes and sections of soldered joints, as well as their mechanical strength, using a 2092 tensile machine equipped with a P772.002 dynamometer with a scale factor of $0.5 \mathrm{~N}$; and tests that involved impacts that were applied crosswise to the board plane with a frequency of 160-180 impacts per minute and an increase of 5-10 ms under overload conditions.

\section{CONCLUSIONS}

(1) It was shown that the traditional method for controlling the temperature of a soldering tool before the soldering procedure does not ensure an optimal temperature of the soldering of unique joints.

(2) The method for maintaining the required soldering temperature based on the selection of an optimal combination of the type and temperature of a soldering tool is inefficient.

(3) The improved method is based on the dependence of the soldering temperature on the thermal characteristics of both a soldered joint and a soldering tool.

(4) It was shown that if the soldering rod is fairly long, i.e., $L \geq 1.6 \sqrt{a \tau_{\mathrm{w}}}$, the cooling of the working end of a soldering tool during a single soldering procedure does not depend on the availability of a thermoregulator in the soldering tool, the tool's power, and the length of the soldering rod.

(5) The effect of the initial temperatures of the soldering rod and soldered joint, the diameters of the soldering rod and wire, as well as the thermal characteristics of the soldering rod and wire materials, on the soldering temperature were found. 
(6) It was shown that during contact with a soldered joint the decrease in the temperature of the working end of a soldering rod is proportional to the cross-sectional area of the wire that is being soldered and inversely proportional to the cross-sectional area of the soldering rod.

(7) The high quality of the soldered joints that were produced with allowance for the relationships we derived was confirmed by the results of complex tests of automatic control units for resistance to mechanical loading in accordance with GOST V20.57.305-98, the results of trial storage and reliability tests of electronic devices, the verification of the mechanical strength of several hundred soldered joints, the visual inspection of several tens of thousands of soldered joints, the examination of their sections and shapes, as well as the study of the appearance of fractured soldered joints.

(8) The relationships we obtained can be used for specifying the design parameters and thermal characteristics of soldering tools in order to improve the quality of the unique soldered joints of artificial satellites.

(9) The use of these solutions makes it possible to substantially reduce the number of defects in soldered joints in electronic devices that operate at elevated temperatures and with high levels of vibration.

\section{REFERENCES}

1. Shcherbinin, V.E., Kostin, V.N., Smorodinskii, Ya.G., Nichipuruk, A.P., Rinkevich, A.B., Shleenkov, A.S., Patramanskii, B.V., and Loskutov, V.E., On necessary measures for ensuring safe operation of pipeline transport using nondestructive testing methods, Russ. J. Nondestr. Test., 2011, no. 12, pp. 842-851.

2. Gorkunov, E.S., Smirnov, S.V., and Rodionova, S.S., Effect of plastic deformation under hydrostatic pressure on damage and magnetic characteristics of 2SP low-carbon steel, Fizicheskaya mezomekhanika, 2003, vol. 6, no. 5, pp. 101-108.

3. Shcherbinin, V.E., Blinov, Yu.I., Shleenkov, A.S., Barmenkov, B.G., and Kostin, V.N., On development of national standards for magnetic and eddy-current nondestructive testing of steel pipes, Russ. J. Nondestr. Test., 2009, no. 10 , pp. $740-742$.

4. Budai, B.T., et al., Development of high-accuracy ecologically safe method for measuring the thickness of rolled sheets, Russ. J. Nondestr. Test., 2012, no. 8, pp. 483-487.

5. Lashko, N.F. and Lashko, S.V., Kontaktnye metallurgicheskie protsessy pri paike (Contact Metallurgical Processes in Soldering), Moscow: Metallurgiya, 1977.

6. Manko, G., Paika i pripoi (Soldering and Solders), Moscow: Mashinostroenie, 1968.

7. Khryapin, V.E., Spravochnik payal'shchika, 5th edition (Solderer's Reference Book), Moscow: Mashinostroenie, 1981.

8. Kutateladze, S.S., Osnovy teorii teploobmena, 2nd edition (Fundamentals of Heat Transfer Theory), Moscow: Mashgiz, 1962.

Translated by D. Tkachuk 